NATIONAL LABORATORY

\title{
Traction Drive and Gearing Design Comparisons for Multiple Manufacturers and Models
}

\section{October 2013}

Prepared by

C.W. Ayers

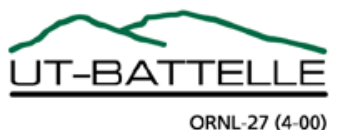




\section{DOCUMENT AVAILABILITY}

Reports produced after January 1, 1996, are generally available free via US Department of Energy (DOE) SciTech Connect.

Website http://www.osti.gov/scitech/

Reports produced before January 1, 1996, may be purchased by members of the public from the following source:

National Technical Information Service

5285 Port Royal Road

Springfield, VA 22161

Telephone 703-605-6000 (1-800-553-6847)

TDD 703-487-4639

Fax 703-605-6900

E-mail info@ntis.gov

Website http://www.ntis.gov/support/ordernowabout.htm

Reports are available to DOE employees, DOE contractors, Energy Technology Data Exchange representatives, and International Nuclear Information System representatives from the following source:

Office of Scientific and Technical Information

PO Box 62

Oak Ridge, TN 37831

Telephone 865-576-8401

Fax 865-576-5728

E-mail reports@osti.gov

Website http://www.osti.gov/contact.html

This report was prepared as an account of work sponsored by an agency of the United States Government. Neither the United States Government nor any agency thereof, nor any of their employees, makes any warranty, express or implied, or assumes any legal liability or responsibility for the accuracy, completeness, or usefulness of any information, apparatus, product, or process disclosed, or represents that its use would not infringe privately owned rights. Reference herein to any specific commercial product, process, or service by trade name, trademark, manufacturer, or otherwise, does not necessarily constitute or imply its endorsement, recommendation, or favoring by the United States Government or any agency thereof. The views and opinions of authors expressed herein do not necessarily state or reflect those of the United States Government or any agency thereof. 
ORNL/TM-2013/482

\title{
Energy and Transportation Science Division
}

\section{Traction Drive and Gearing Design Comparisons for Multiple Manufacturers and Models}

\author{
Author(s) \\ C.W. Ayers
}

Date Published:

October 2013

Prepared by

OAK RIDGE NATIONAL LABORATORY

Oak Ridge, Tennessee 37831-6283

managed by

UT-BATTELLE, LLC

for the

U.S. DEPARTMENT OF ENERGY

under contract DE-AC05-00OR22725 



\section{CONTENTS}

$\begin{array}{rll}\text { Page } & \end{array}$

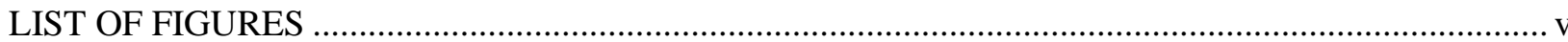

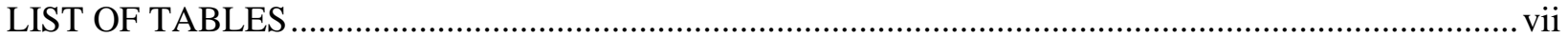

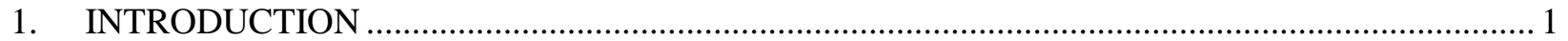

2. DRIVETRAIN STUDY AND COMPARISON OF ORNL-BENCHMARKED VEHICLES.............. 3

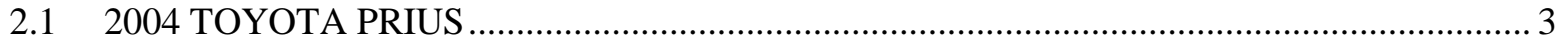

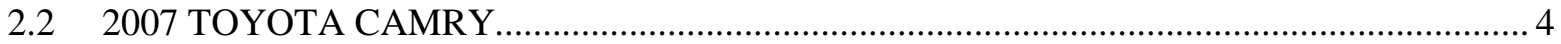

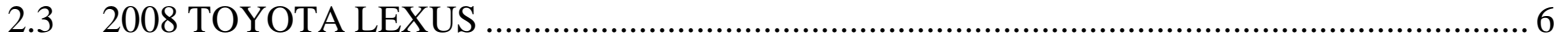

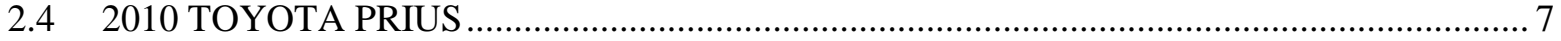

2.52011 HYUNDAI SONATA

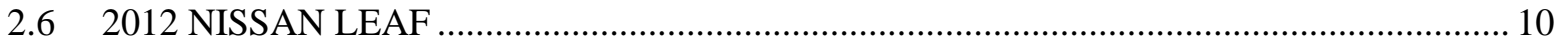

3. EVALUATION OF SOA HIGH SPEED STARTERS AND ALTERNATORS .............................. 13

3.12010 CAMRY 12 VOLT DC COMMUTATED STARTER MOTOR .................................... 13

3.2 DIXIE ELECTRIC STARTER \#250-45201…..................................................................... 14

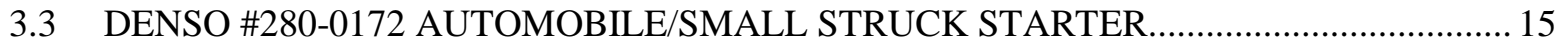

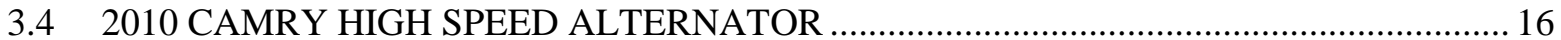

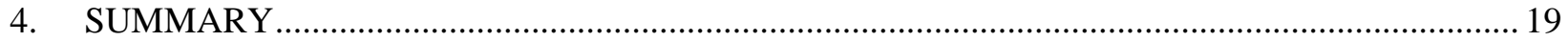

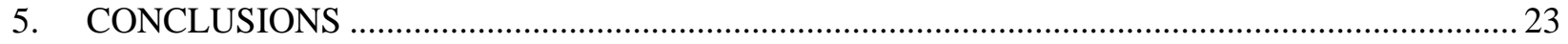

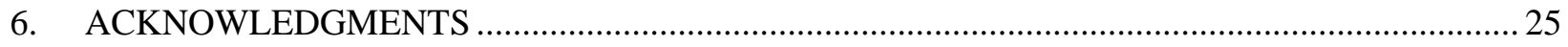

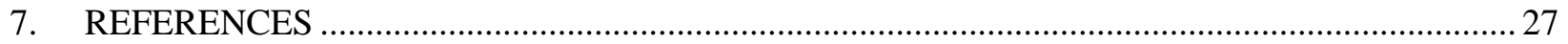





\section{LIST OF FIGURES}

Figure

Page

1. View of open 2004 Prius geartrain............................................................................... 4

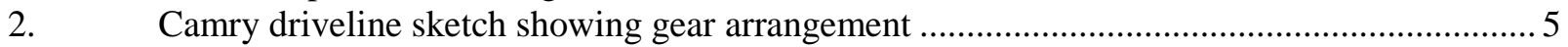

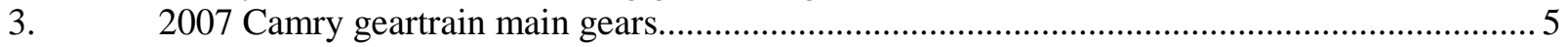

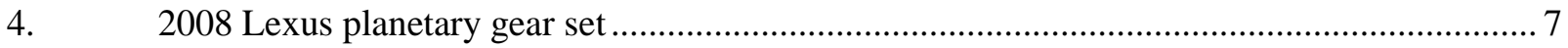

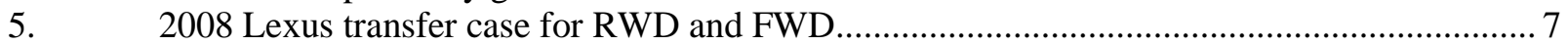

6. $\quad 2010$ Prius driveline showing gearing requirements related to shaft offset........................... 8

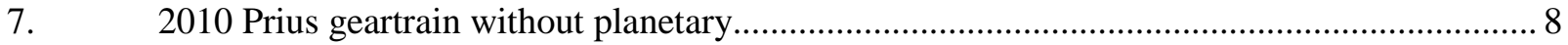

8. 2011 Hyundai Sonata traction drive clutch/planetary section ................................................ 9

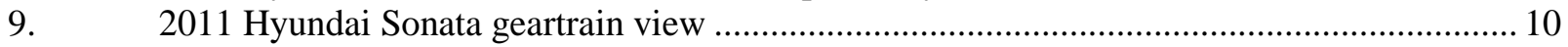

10. 2012 LEAF geartrain diagram showing gear arrangement and tooth counts ......................... 10

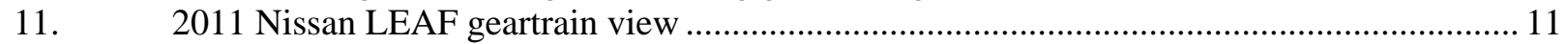

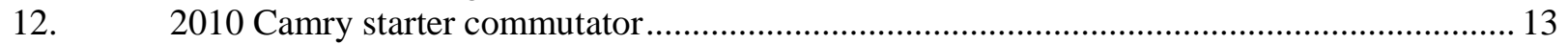

13. 2010 Camry high speed starter and in-line planetary gear set............................................... 14

14. Dixie Electric high speed starter with in-line planetary gear set........................................... 15

15. Denso \#280-0172 high speed starter and offset gear set ................................................. 16

16. 2010 Camry high speed alternator, approximately $12000 \mathrm{rpm}$ max speed ........................... 17

17. Graph of traction motor power density relationship to shaft speed........................................ 21 



\section{LIST OF TABLES}

Table

Page

1. Comparison chart for traction drives and starters......................................................... 20

2. Power density comparison of several hybrid/electric vehicles.......................................... 21 



\section{INTRODUCTION}

Hybrid vehicle traction driveline gearing has evolved over the last decade or so to match ever increasing speeds for their motors and generators. Auto manufacturers are using increased speed as a means to increase power density of their electric traction motors in vehicles. Oak Ridge National Laboratory (ORNL) is also pursuing traction motor designs that have much higher maximum rotor speeds, in the range of 15,000 - 25,000 rpm.

Improved gearing is needed to reduce the higher rotor speeds to match the final drive and wheel speed requirement which does not change. Speed for starters and alternators is also increasing in auto designs, so high speed rotors and gearing for speed reduction are being developed in that automotive area as well. These efforts focus on increasing power density, making motors and generators smaller, reducing or eliminating the need for magnet material, and reducing overall amount of materials that is required to produce these products (such as copper, silicon steel, etc.). This reduces the cost of the hybridized vehicle as well as reducing the weight.

Replacing conventional oversized motors with smaller motors using speed-reduction gearing has inherent design and cost tradeoffs. Traction drives benchmarked by ORNL over the last several years, and some state-of-the-art (SOA) starters/alternators will be examined to see how cost/volume engineering tradeoffs are being made that allow the industry to keep using smaller and smaller electric machines in their automotive designs. The study will look at number of gears in the drivetrain, as well as manufacturing methods being used and how this may affect the cost of added gearing.

Lessons learned from this study will benefit ORNL's designs for high speed motors. It will also provide valuable insight for the best means of matching the new higher speed motors to existing drivelines in the gear train of automotive traction drives. 


\section{DRIVETRAIN STUDY AND COMPARISON OF ORNL-BENCHMARKED VEHICLES}

Several hybrid vehicle traction drives have been benchmarked by ORNL over the past decade. These range from MY2004 vehicles to the present from Toyota, Hyundai, Lexus, and Nissan. Below are observations made from examining all these traction drives side-by-side to look at numbers and types of gears, whether the use of planetaries is incorporated or not, types of bearings and lubrication, and gear manufacturing methods (conventional, high-tolerance, expensive) etc.

This review looks at the 2004 and 2010 Toyota Prius, the 2007 Toyota Camry, the 2008 Lexus, the 2011 Hyundai Sonata, and the 2012 Nissan LEAF traction drives. In addition, several high speed engine starters are evaluated to see design trends in this industry.

\subsection{TOYOTA PRIUS}

The 2004 Prius traction drive was the first system to be benchmarked by the Advanced Power Electronics and Electric Machines group (APEEM) at ORNL. This traction drive is made up of six gears, four helical and two spur style which are used to couple a chain between the motor shaft and the lead gear in the drive train. The chain drive concept, which was dropped in subsequent years, was most likely utilized to offset the fairly large diameter motor from the axle axis. The 2004 Prius has the largest diameter motor of any of the benchmarked traction drive systems. A photo of the opened traction drive can be seen in Figure 1 below. See references [1] and [2] for further information on the Prius designs and benchmarking work.

There is no planetary reduction at the motor shaft for this gear train, although a planetary set is used between the engine, generator, and motor to provide power split capability. This planetary is not of interest to this study.

The differential gear has 75 teeth, helical gear style. The ratio calculated from the motor shaft to the differential is $\underline{\mathbf{4 . 1 1} \text { to } \mathbf{1}}$. All the other gears are conventional helical gears, and the tooth surface appearance shows conventional cutting methods and grinding from typical gear blanks. The chain gears are straight tooth spur gears for coupling into the chain links.

The bearings in this gear train are typical bearings, some ball type and some roller type, although they are proprietary models and usually non-standard sizes. They are oiled by splash or drip with the automatic transmission fluid (ATF) used for both lubrication and cooling throughout the whole traction drive.

The 2004 Prius motor was designed for $6000 \mathrm{rpm}$, so at peak motor speed the gear reduction of 4.11 will produce an axle speed of approximately $1460 \mathrm{rpm}$. The 2004 Prius drivetrain has 6 gears and one chain in line from the motor shaft to the differential. 


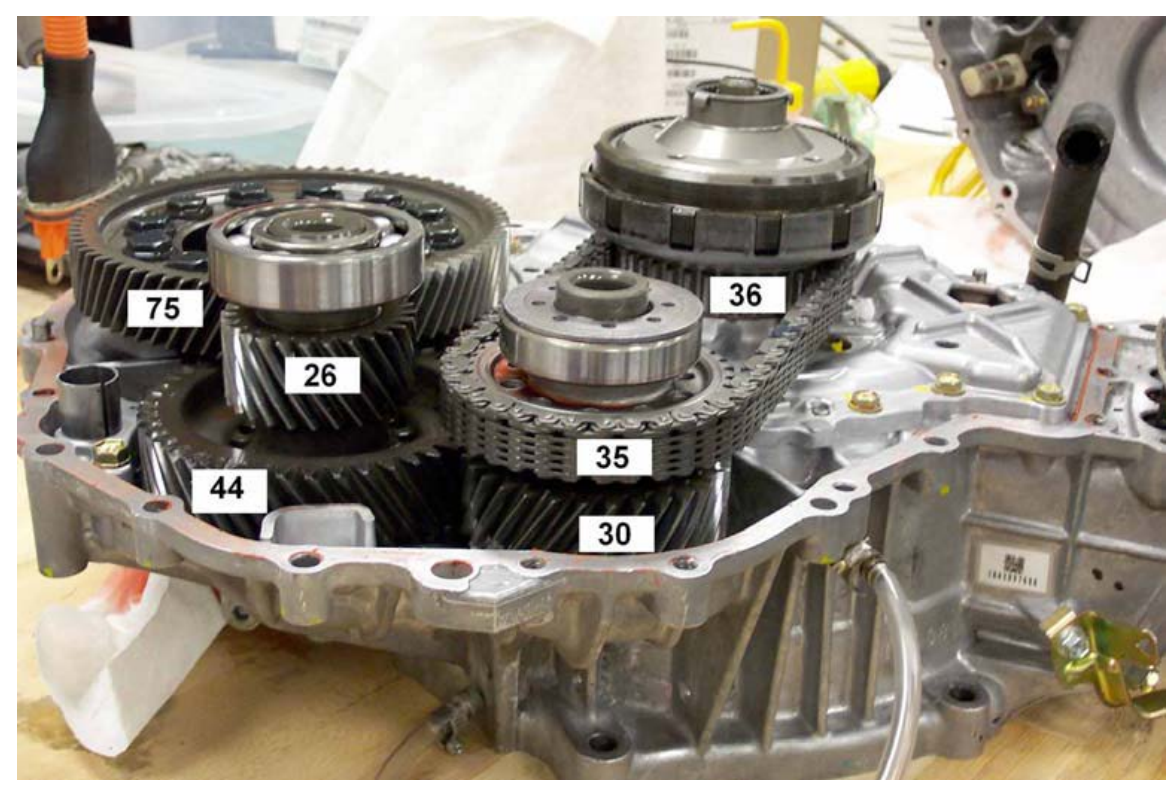

Fig. 1. View of open 2004 Prius geartrain

\section{$2.2 \quad 2007$ TOYOTA CAMRY}

The Camry drive utilizes a double planetary design, one of which is used for direct motor speed reduction into the gear train to the differential. The second planetary in the dual package connects the generator and the engine into the drive train as a power-split device, same as was used in the 2004 Prius. The motor (reduction) planetary gear set uses a fixed carrier, with the sun being the input from the motor shaft and the ring gear engaging into the gear train to the differential. A hand-rotation count for the gear ratio showed a reduction from the motor shaft to the differential of $\mathbf{8 . 8}$ to 1. Further information from previous ORNL benchmarking work is available on the Camry in reference [3].

There are four main gears after the motor planetary ring gear. These appear to be fabricated with typical hobbing or shaping of standard gear blanks, all helical gears, with standard finish grinding. The bearings for this system are ball and roller/tapered roller bearings, oiled by splash or drip from the traction drive ATF.

The main gear tooth counts are (starting from the motor ring gear) 54T, 55T, 23T, and 80T (see Figure 2 below). The gear ratio for these gears calculates to be a 3.543 speed reduction. The first gear mesh does very little speed reduction, but apparently serves to offset the motor/stator axis from the axle/differential carrier axis. If this were not a geometric constraint, the gear train could be designed with only the planetary and two reduction gears, i.e. 23T on the motor end and $80 \mathrm{~T}$ on the differential. A photo of the main gears (planetary not shown here) is depicted in Figure 3. 


\section{Camry Driveline from Motor to Axle:}

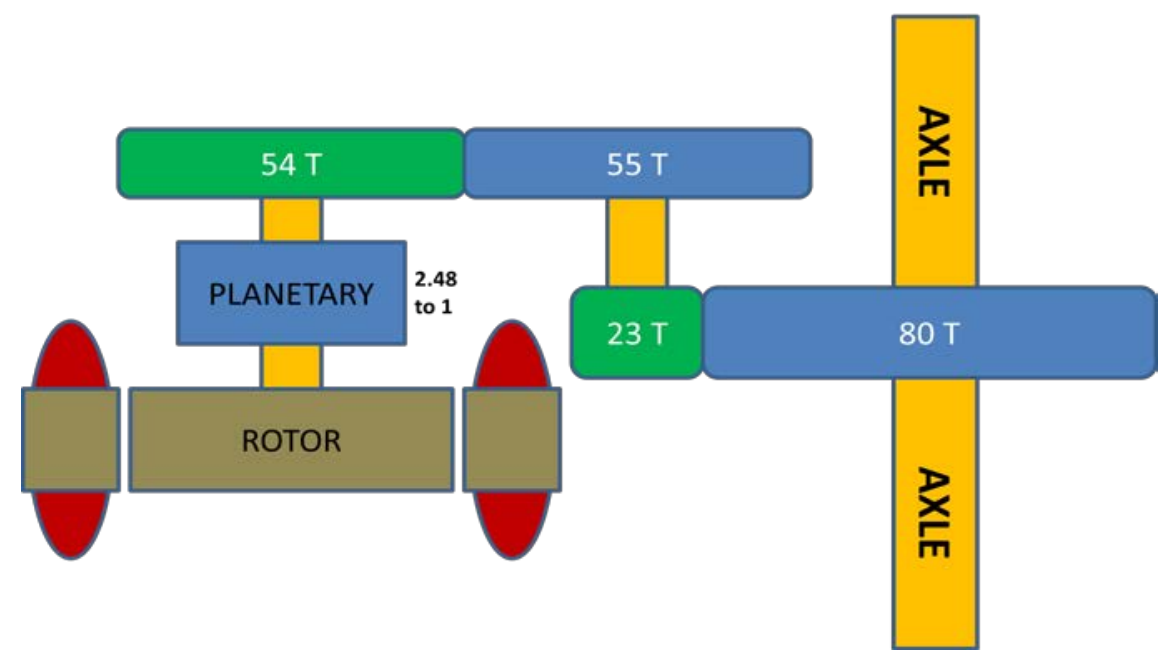

Fig. 2. Camry driveline sketch showing gear arrangement

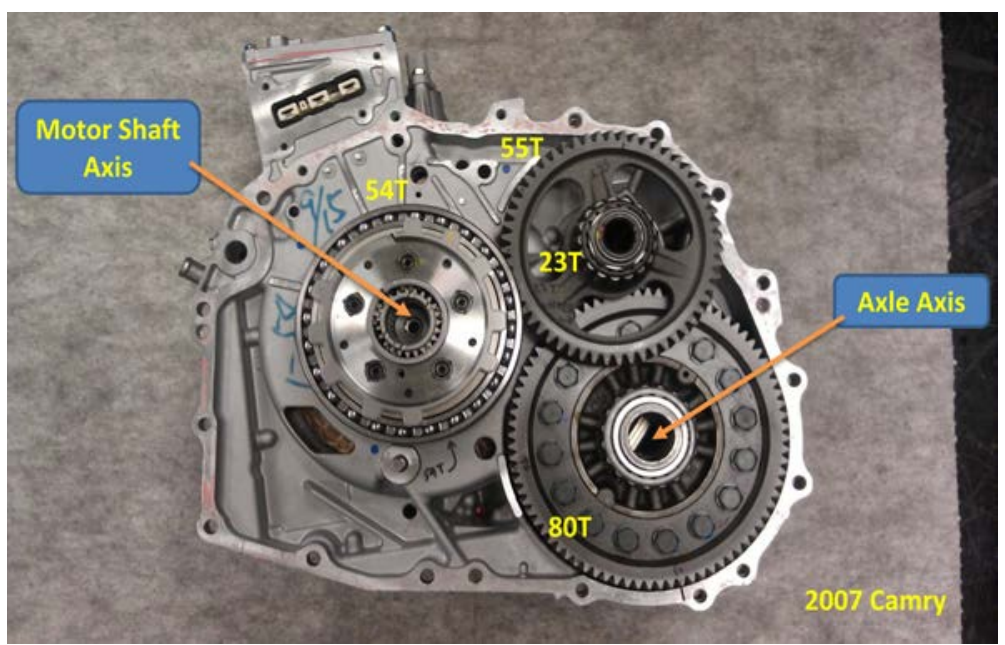

Fig. 3. 2007 Camry geartrain main gears

Calculations of bearing speeds were performed for the high speed end of the system, i.e. at the motor shaft and planetary. The sun gear has $\mathrm{S}=23$ teeth, the planets have $\mathrm{P}=18$ teeth, and the ring gear has $\mathrm{R}=$ 57 teeth.

The sun gear, attached to the motor shaft, will run at a maximum of 14,000 rpm, so the shaft bearing will require a 14,000 rpm speed rating. This bearing is a proprietary component, so specifications are not available. The size, though, fits between two standard catalog ball bearings that have speed ratings of 11,000 and 13,000 rpm, so by interpolation this bearing would be rated at 12,000 rpm with light oil lubrication. The proprietary bearing may have certain unknown design characteristics that push the design speed up to the motor rating of 14,000 rpm, or the low duty cycle at maximum motor speed may allow a 12,000 rpm bearing to have an acceptable life cycle. A higher precision fabrication for this geometry could raise the speed rating a large degree with some added cost. The bearing utilizes a plastic molded cage, that appears to be glass or ceramic filled for stiffness and higher temperature stability.

The relationship for gear speeds in a planetary gear train is: 


$$
(\mathrm{R}+\mathrm{S}) * \omega_{\text {carrier }}=(\mathrm{R}) * \omega_{\text {ring }}+(\mathrm{S}) * \omega_{\text {sun }}
$$

This Camry design uses a fixed carrier, so the planet gears rotate only around their own center and will spin at a ratio of ring teeth to planet teeth:

$$
\omega_{\text {planet }}=\omega_{\text {ring }} * \mathrm{R} / \mathrm{P}
$$

To calculate gear ratios, we can use equation (1) and set $\omega_{\text {carrier }}=0$ since the carrier is grounded. We can then set $\omega_{\text {ring }}$ to 1 and calculate $\omega_{\text {sun }}$ to get motor turns relative to output turns. $R=57, S=23$, so $\omega_{\text {sun }} / \omega_{\text {ring }}=-2.478$. The negative sign indicates the output rotates in the opposite direction to the input shaft. Total gearbox ratio from the motor to the differential will then be $2.478 \times 3.543=\underline{\mathbf{8 . 7 8}}$ to 1 reduction from motor to differential (confirming the hand rotation count above).

For ring gear speed at maximum motor speed use eqn 1 , with $\omega_{\text {carrier }}=0$

$$
\begin{aligned}
& (\mathrm{R}) * \omega_{\text {ring }}+(\mathrm{S}) * \omega_{\text {sun }}=0, \text { or } \\
& \omega_{\text {ring }}=(\mathrm{S} / \mathrm{R}) * \omega_{\text {sun }}=5649 \mathrm{rpm} .
\end{aligned}
$$

From this, and using eqn 2 , we can calculate $\omega_{\text {planet }}=17900 \mathrm{rpm}$, which is significantly higher than the motor speed. The bearings for the planets are much smaller diameter than the motor output shaft, so can have a significantly higher speed range. These are needle bearings, the use of which is common throughout all the planetary sets studied, with dimensions of approximately $15 \mathrm{~mm}$ ID and $22 \mathrm{~mm}$ OD. This is close to a commercially available needle bearing that has a speed rating of 17,000 rpm when using oil for lubrication, so this bearing design is right at the speed limit.

The Camry motor maximum speed is $14,000 \mathrm{rpm}$, so the shaft speed is reduced to about $1,600 \mathrm{rpm}$ at the axle. The 2007 Camry has seven total gears in line from the motor shaft to the differential.

Overall, this 2007 Camry traction drive is seen to use conventional bearings and conventional gear manufacturing methods - component speeds have been designed with maximum speeds that match very closely to the bearing maximum allowable speeds. Light viscosity oil by splash and drip is used to lubricate the gears and the bearings. The maximum axle speed based on the above observations is designed to be about 1,600 rpm.

\section{$2.3 \quad 2008$ LEXUS}

This traction drive is from a high performance hybrid vehicle, the 2008 Lexus. The overall shape of the driveline is very different, providing all-wheel drive, and it extends in a long slender shape as opposed to the boxy shape of the other drives that were evaluated. All the other drives were packaged for a normal front-wheel drive vehicle where package shape and axial length are critical (basically between the front wheels). The photograph in Figure 4 shows the complex planetary from the Lexus. Speed reduction from motor to transfer case is accomplished via a complex planetary called a Ravineaux Gear. This vehicle has a fairly complex driveline so is much more costly than most of the other drivelines reviewed here. See the ORNL TM report in reference [4] for further details on the Lexus gear train. 


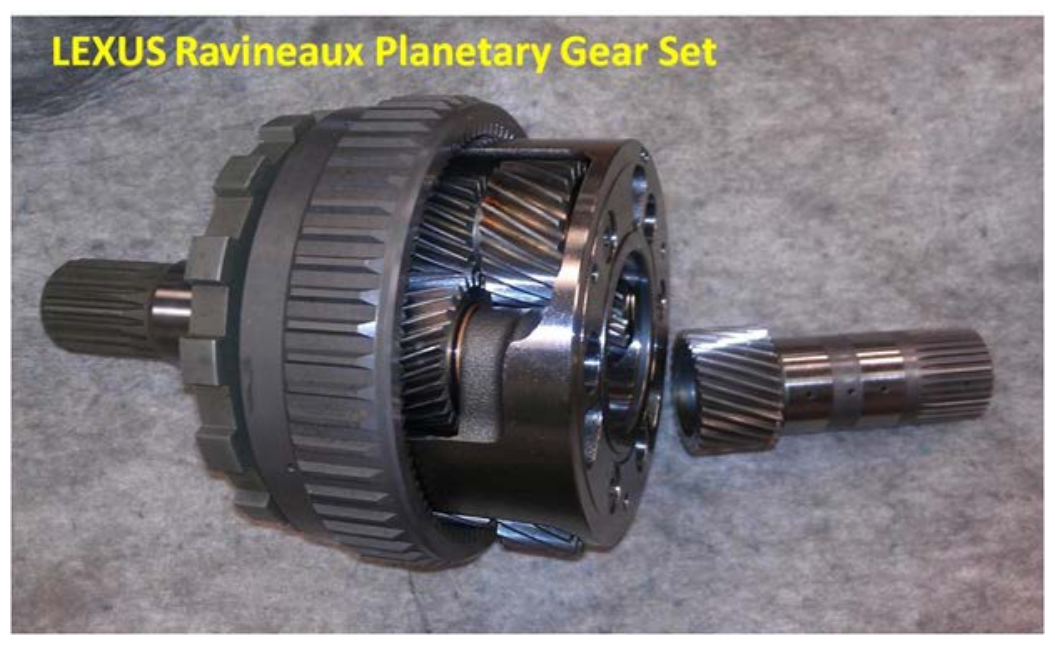

Fig. 4. 2008 Lexus planetary gear set

Figure 5 shows the transfer case for the Lexus, a drive segment not required in any of the other benchmarked models since this drive is for front and rear wheel drive.

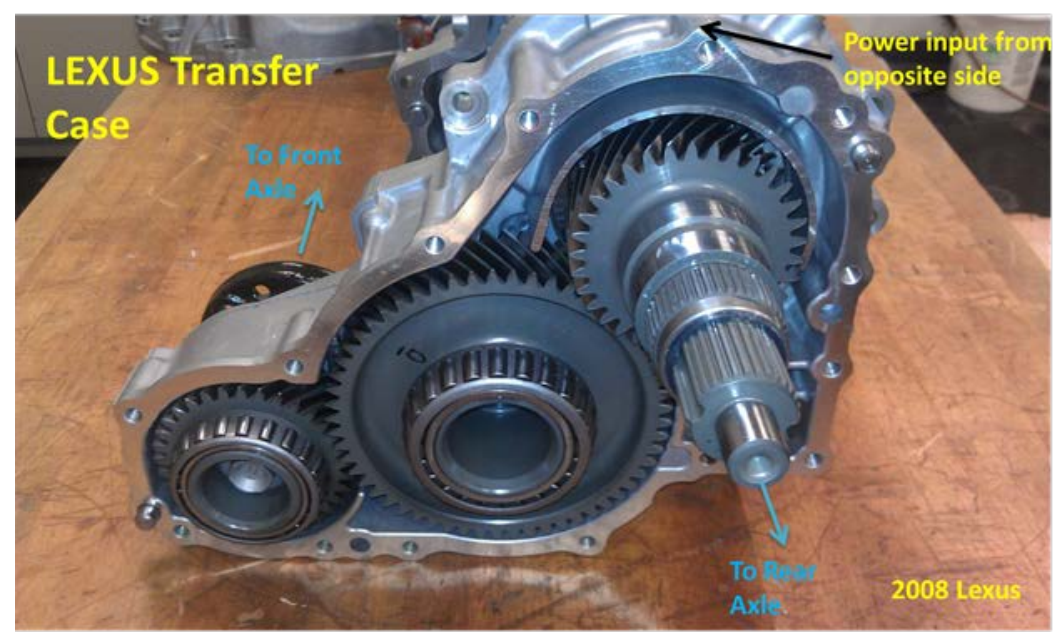

Fig. 5. 2008 Lexus transfer case for RWD and FWD

\subsection{TOYOTA PRIUS}

The 2010 Prius traction drive utilizes a planetary set leading from the motor shaft to the gear train for the primary speed reduction from this high speed motor. The carrier is fixed, the sun is on the motor shaft, and the ring gear leads into the gear train to the differential. This is the same scenario as the 2007 Camry reduction planetary, and is almost identical in size and gear design. The sun gear has 22 teeth, the planets have 18 teeth, and the ring gear has 58 teeth. Using the planetary ratio relationship above, the reduction for the 2010 Prius motor planetary is 2.636 to 1 .

The four main gears in this drive are very similar in size, manufacturing, and tooth counts to the 2007 Camry. Starting from the motor ring gear, the gears (shown in Figure 6) have 54T, 55T, 24T, and 77T. The reduction ratio of this group of gears calculates to be $77 / 24 * 55 / 54=3.268$ to 1 . As in the case of 
the Camry, since these two gearboxes are almost identical, the extra two gears in the driveline could be eliminated if the physical offset between axle and motor stator were not required. This might be able to be accomplished in an all-electric vehicle where the volume of the internal combustion engine is removed from the driveline, allowing components to be positioned differently. Figure 7 shows a photo of the main gears for the 2010 Prius driveline - note the similarity between this gear set and that seen in the Camry (Figure 3 above).

\section{PRIUS Driveline from Motor to Axle:}

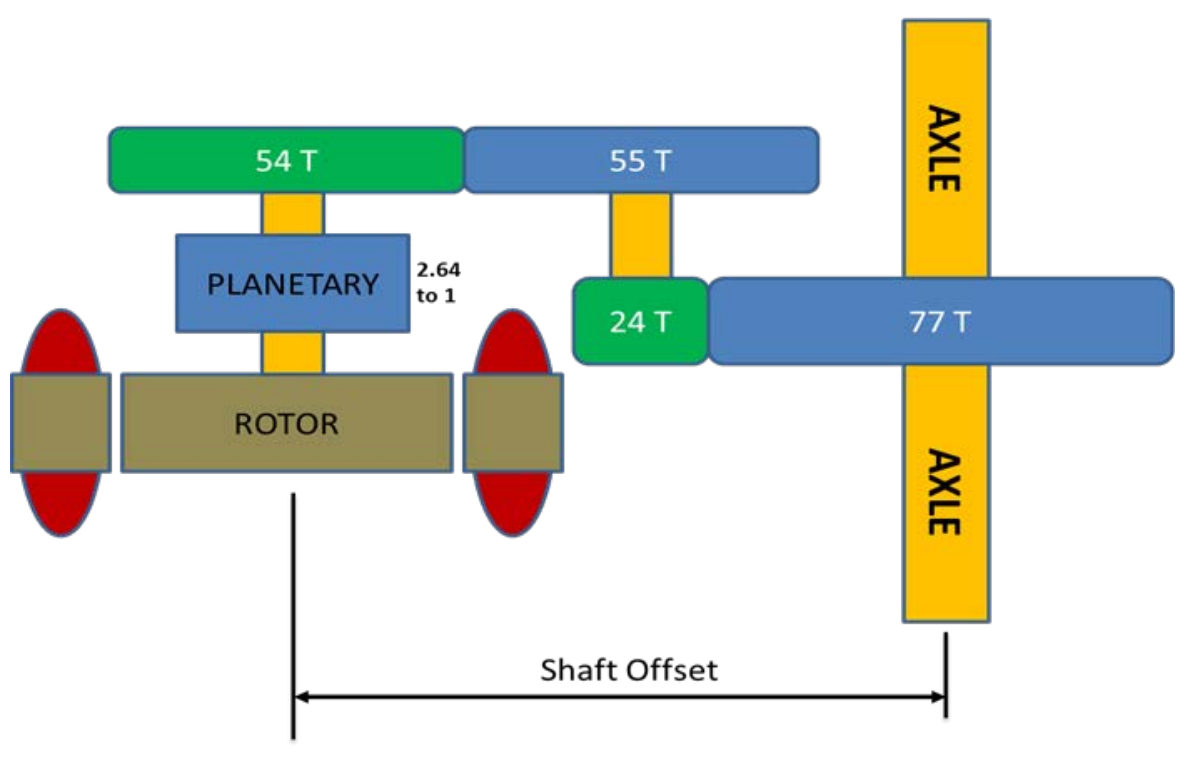

Fig. 6. 2010 Prius driveline showing gearing requirements related to shaft offset

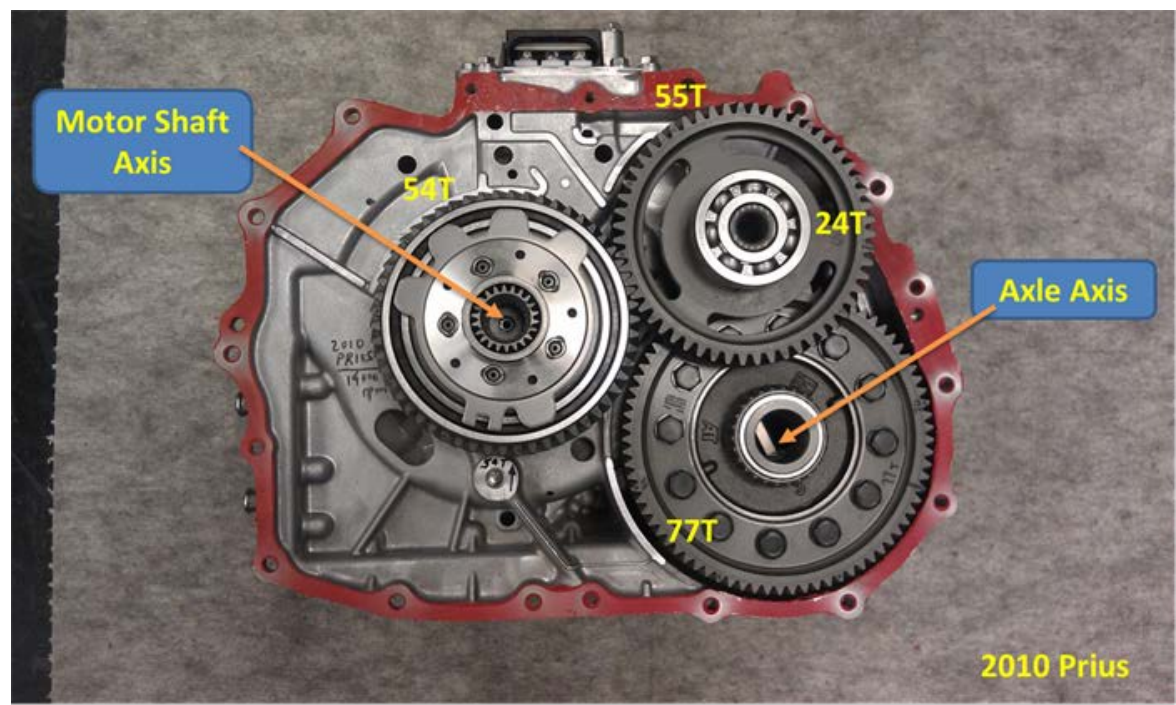

Fig. 7. 2010 Prius geartrain without planetary shown

The total speed reduction from the motor to the differential in this drive is $\mathbf{8 . 6 1 4}$ to $\mathbf{1}$. The maximum speed for the 2010 Prius motor is $13,500 \mathrm{rpm}$, so the maximum axle speed will be 1,570 rpm - very close 
to the number calculated for the 2007 Camry, and just a little above the 2004 Prius (1,460 rpm). The 2010 Prius has seven gears in line from the motor to the differential, same as the 2007 Camry.

Overall, the 2010 Prius traction drive is found to be extremely similar to the 2007 Camry, with no evolution in the design and no revolutionary design changes. The gears are conventionally manufactured and bearings are very conventional. Sitting side-by-side with the Camry drive, they look almost the same - the number of gears is the same, gear tooth counts are almost identical, etc. Thus, component speeds and bearing max speeds are matched closely as well, and lubrication is identical. The maximum axle speed is $1570 \mathrm{rpm}$. These two gearboxes are different from the 2004 Prius in that they moved away from the chain in the driveline, and there is a planetary required due to the major increase in the motor speed for the 2007 Camry and the 2010 Prius (>2x increase).

\subsection{HYUNDAI SONATA}

The Hyundai Sonata traction drive is basically a large automatic transmission, with six speed changes available in the driveline. It contains five sets of clutches, and two planetary gear sets. The main planetary gear set, connected directly to the motor shaft has a sun gear with 25 teeth, dual planets with 20 and 21 teeth (from sun to ring respectively), and a ring gear with 76 teeth. The final drive gear at the axle has 53 teeth, much coarser than most of the other drives that contain between 70 and 80 teeth.

The differential end of the driveline looks similar to other electric traction drives, but the initial sections at the motor end are all in line with the motor shaft axis, with planetaries and clutches all on that axis. In comparison with the LEAF, this gearbox is extremely complex with 3-4 times the number of moving parts, many additional bearings, and multiple wet clutches for gear changes. The photo of Figure 8 below shows the clutch and planetary section for the Sonata.

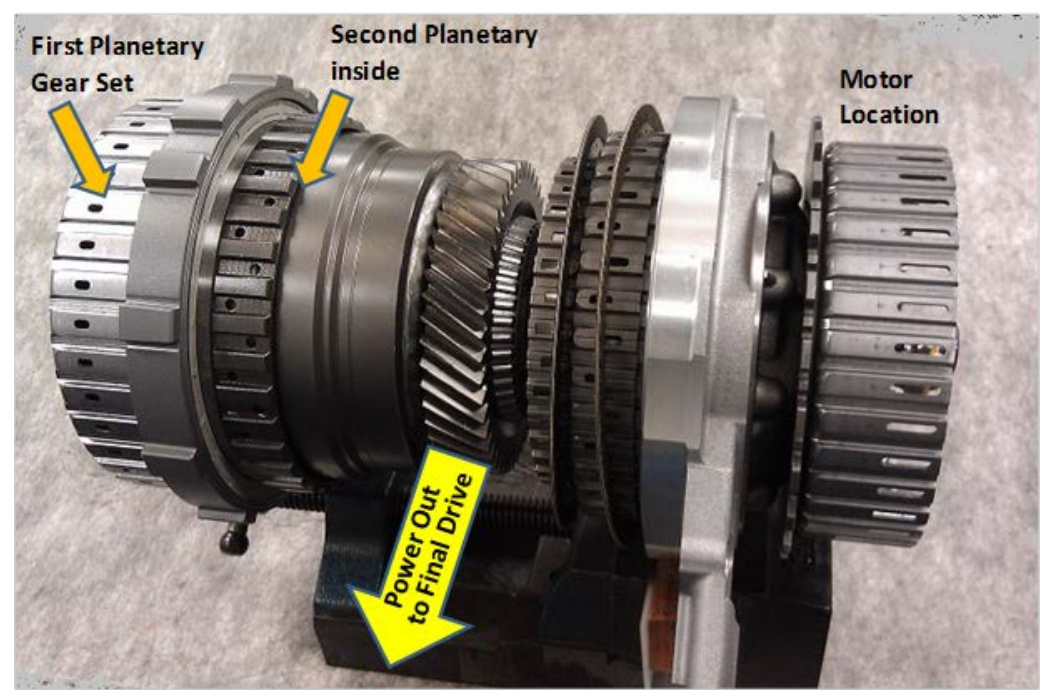

Fig. 8. 2011 Hyundai Sonata traction drive clutch/planetary section

The gear manufacturing appears to be done using gear shaping and grinding of normal cast blanks, similar to the other benchmarked drive units. Bearings are conventional taper roller, ball bearing, and needle bearings. After the planetary in the Sonata, there are 4 gears in line. In any particular "speed" position, there will be a planetary in line, adding three gears to the four, making seven gears in line from the motor to the main axle gear for the Sonata. The Figure 9 photo shows the main gear section for the Sonata, downstream in the driveline from the clutch/planetary section. 


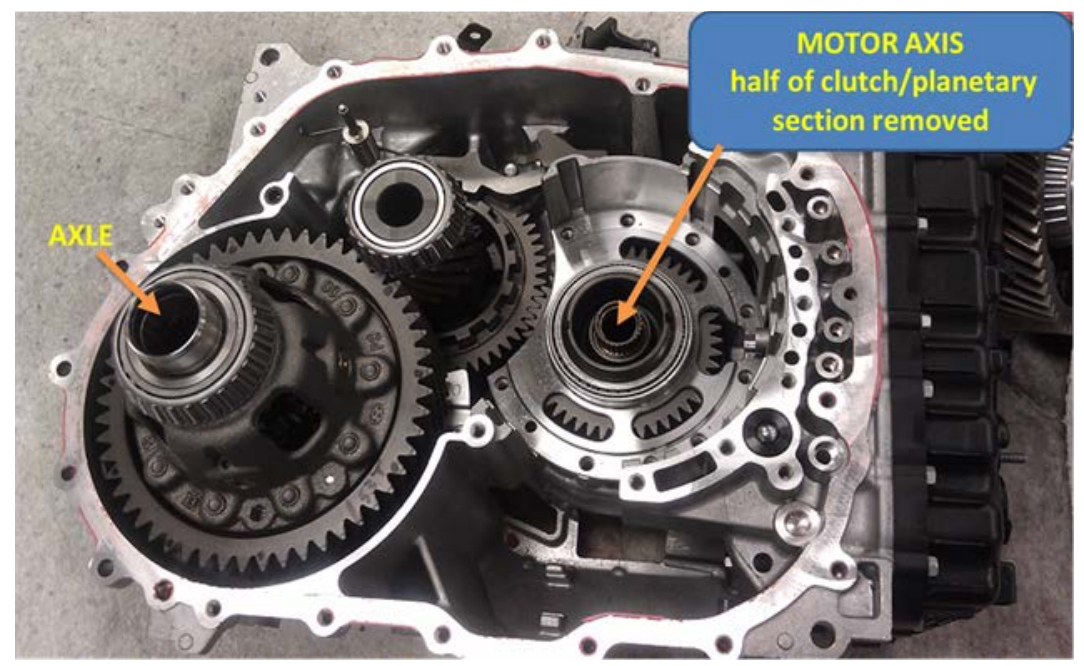

Fig. 9. 2011 Hyundai Sonata geartrain view

\subsection{NISSAN LEAF}

This LEAF drive is the only one benchmarked for an All Electric Vehicle (AEV). This drivetrain has four main gears in the gearbox, but utilizes NO planetary gear set in the gearing system. The motor runs at a moderately high speed of 10,400 rpm, which is about 4,000 rpm less than the 2007 Camry and the 2010 Prius. The total gear reduction is $\mathbf{7 . 9 3}$ to 1 , calculated from the gear tooth counts (see Figure 10 below). The motor is continuous direct drive to the axle, with no power split required as in the previous cases since this is an all-electric vehicle with no internal combustion engine. The main bearing at the motor shaft gear is a ball bearing, oil lubricated from the gearbox lubricant. It has similar geometry to a 6207 ball bearing which specifies a maximum speed of 11,000 rpm for oil lubricated operation. This matches well with the maximum stated speed of the LEAF of 10,400 rpm, and there are no extremes in operating condition for this bearing design.

2012 LEAF Driveline from Motor to Axle:

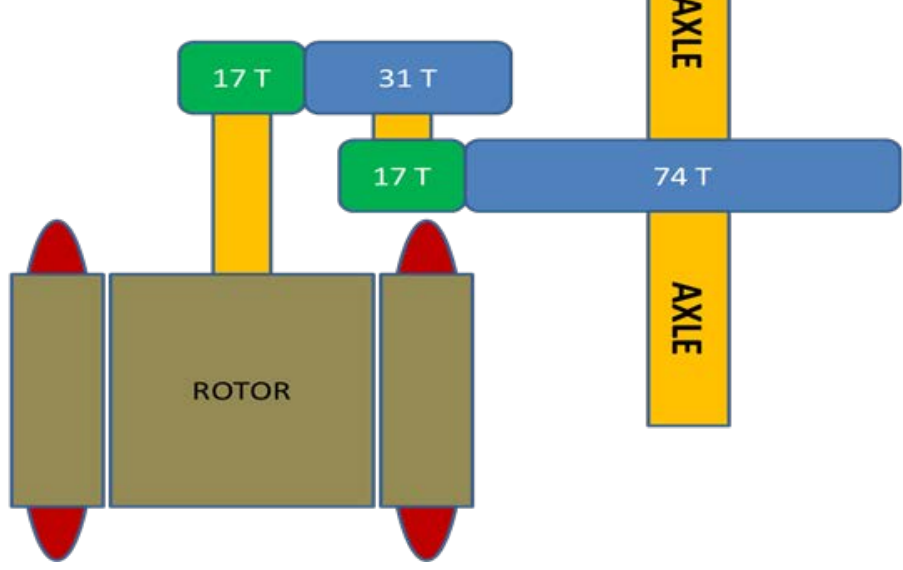

Fig. 10. 2012 LEAF geartrain diagram showing gear arrangement and tooth counts 
Figure 11 shows a photo of the main gears in the driveline, noting that there is no planetary utilized in this gear set, and the simplicity can be seen in this drive compared to the other drives.

With construction, fabrication, and bearings being very similar to other drives in this report, this unit is considered the most cost competitive of the group. From the motor to the main axle (74T) gear, there are four total gears in line.

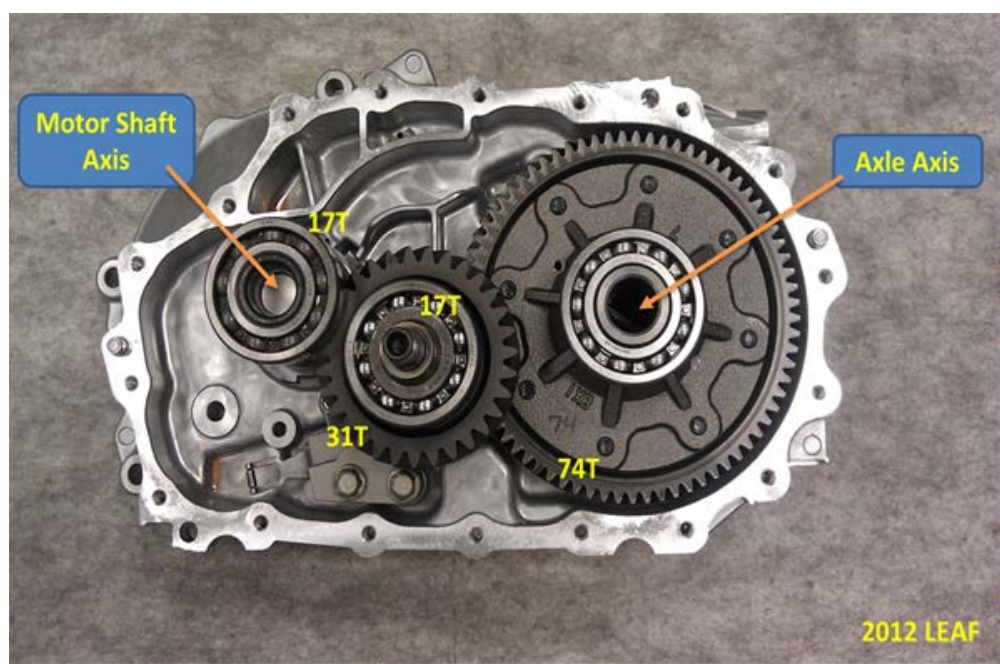

Fig. 11. 2011 Nissan LEAF geartrain view 


\section{EVALUATION OF SOA HIGH SPEED STARTERS AND ALTERNATORS}

\subsection{EVALUATION OF SOA HIGH SPEED STARTERS AND ALTERNATORS}

This starter motor is a 1.990" diameter rotor, with a 1.070" stack length. The small output shaft is 0.242 " in diameter. The motor is commutated axially on the back end of the motor as opposed to the conventional radial configuration commutator. Figure 12 shows the axial commutator on the outboard end of the rotor.

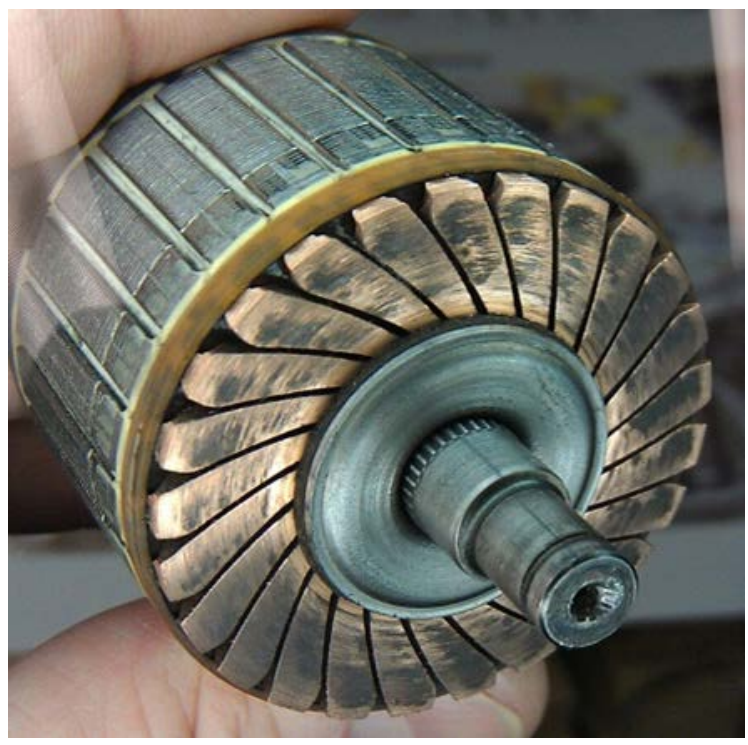

Fig. 12. 2010 Camry starter commutator

The gear reduction for this motor from rotor to output of the starter assembly (i.e. prior to engine ring gear) is 7.875 where the ring gear is fixed. With an approximate engine ring gear reduction ratio of 11 , the total reduction from engine crankshaft to starter rotor would be 87 to 1 . Assuming a typical cranking speed for engines to be around $200 \mathrm{rpm}$, the calculated speed for this Camry starter will be at least 17,000 rpm.

An interesting manufacturing method found on this rotor is the forged sun gear (see Figure 13), made integrally into the rotor shaft - this is the highest speed gear in the system. Finishing operations for the spindle and bearing surfaces for the rotor were performed after the gear was forged, but the gear surfaces look as if they were left as-forged.

The planet gears for this unit appear to be manufactured in a single step, and no after finishing is visible on the surfaces of the teeth. There are three planet gears in this design. All gear surfaces are grainy in appearance (tooth tips, tooth faces, gear ends) and under magnification some porosity is visible indicating that these gears are probably fabricated using powder metallurgy techniques. The ring gear is obviously made of plastic, and scrapings indicate heavy glass or other filler to provide a hard, high strength material. The gear and its support shoulder are all molded together, helping to keep this starter light and lower cost.

All the gears in this Camry starter planetary are greased for lubrication. 


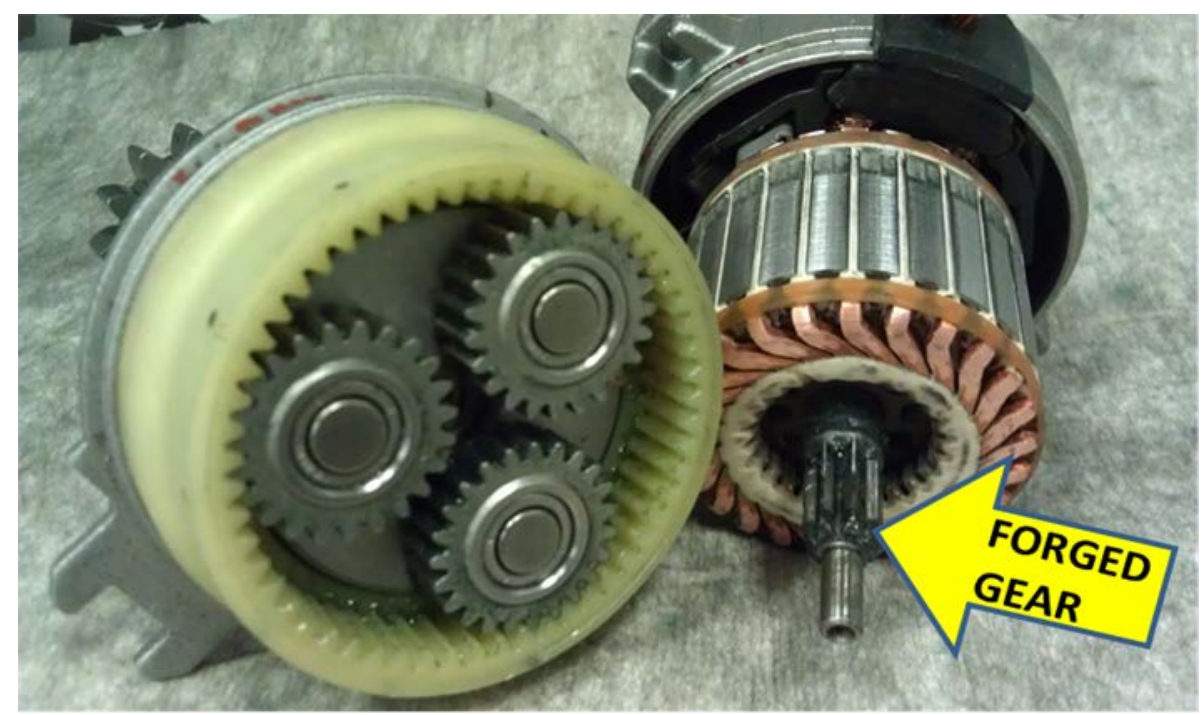

Fig. 13. 2010 Camry high speed starter and in-line planetary gear set

\subsection{DIXIE ELECTRIC STARTER \#250-45201}

This dc starter, like the 2010 Camry starter, was found also to utilize an in-line planetary gear set to reduce output shaft speed (appears to be sized for large diesel engines). This planetary exhibits a speed reduction of 4.29 to 1 (the ring gear is fixed in this design). Using the speed relationship above, this starter motor will rotate at about 9,300 rpm to crank an engine at $200 \mathrm{rpm}$ so this is a relatively high speed motor.

The sun gear for the Dixie Electric starter is machined directly into the rotor shaft. Axial grooving in the gear teeth indicates that gear shaping was used to form the teeth, with minimal or no after grinding. The ground rotor spindle tip runs on needle bearings. See Figure 14 for a photograph of the Dixie Electric starter gear box opened up. 


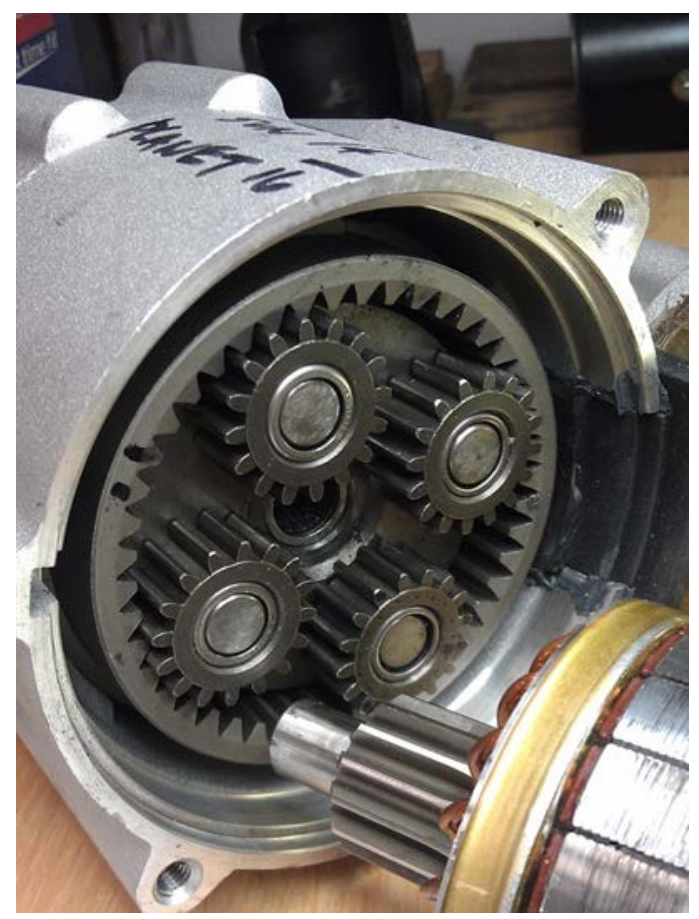

Fig. 14. Dixie Electric high speed starter with in-line planetary gear set

This unit carries four planet gears which appear to be shaped from cast gear blanks (no porosity seen in the gear surfaces). The planetary gear bearings are also needle bearings. All the bearings and gears in this unit are greased for lubrication.

The rotor is 2.675 ” in diameter, and has a stack length of 2.425 ”. The output shaft is approximately 0.7" diameter. The commutator for this machine is the conventional radial-brush commutator off the end of the rotor.

\subsection{DENSO \#280-0172 AUTOMOBILE/SMALL TRUCK STARTER}

This starter does not utilize a planetary gear set for speed reduction. It has 3 gears with offset shafts for reducing motor speed to the output shaft. The pinion gear has 9 teeth, and appears to be forged directly on the rotor shaft blank, with the forging operation producing the final operating gear tooth finish. The rotor runs on typical greased ball bearings.

The companion gear to the pinion has 26 teeth and appears to be fabricated using powder metallurgy techniques - the surfaces show occlusions and porosity (see Figure 15). The companion gear appears to be used as-formed with no after finishing of the teeth, and runs on needle bearings in a plastic cage. The starter output gear (40 teeth) mated with the companion gear, appears to be a cast gear blank. The end faces of the gear are machined, but the teeth look like the original casting surfaces - a little rough, but no porosity or occlusions on the teeth or machined faces (implying cast blanks). This gear runs on a greased ball bearing like the rotor.

The reduction in speed from the motor to the ring gear is 4.44 to 1 . Using the same engine speed/ring gear relationship above, this motor is estimated to run at 9,060 rpm assuming an engine cranking speed of $200 \mathrm{rpm}$.

This unit has a rotor diameter of 1.940” and a stack length of 1.317”. The output shaft diameter at the root of the forged gear is 0.58 ". 


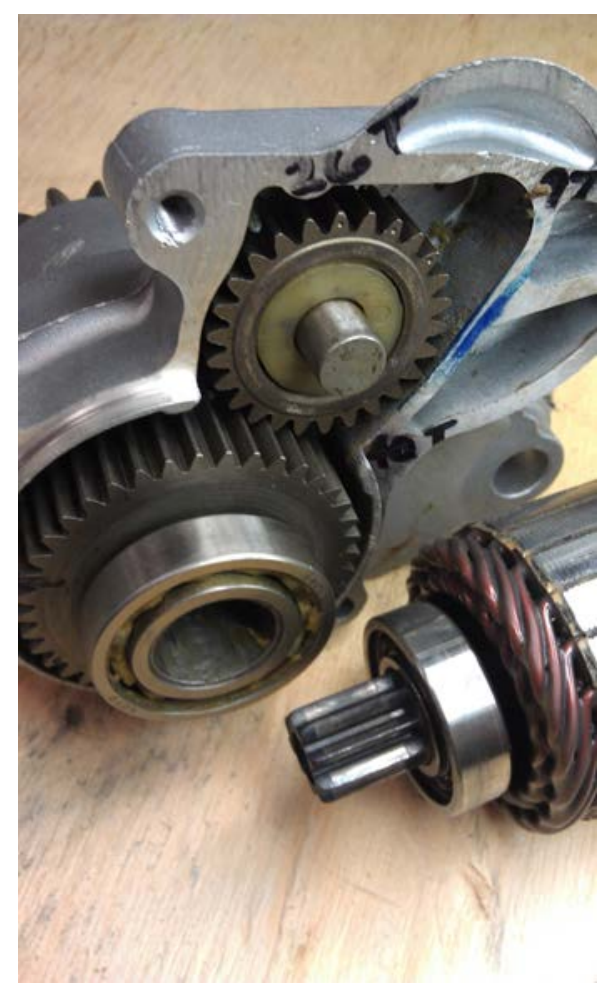

Fig. 15. Denso \#280-0172 high speed starter and offset gear set

\subsection{CAMRY HIGH SPEED ALTERNATOR}

Estimating alternator speed based on pulleys and belt speed: Use as an estimate approximately a 5” diameter crank pulley and a maximum engine speed at about $5000 \mathrm{rpm}$. From these assumptions, belt speed will be $1,310 \mathrm{in} / \mathrm{sec}$. Alternator pulley is 2 in pitch diameter. The alternator speed based on max engine speed of 5,000 rpm will be 12,500 rpm.

Bearings are sealed greased type. Shaft size is about $16 \mathrm{~mm}$, so a standard greased ball bearing speed rating can reach up to 20,000 rpm. Figure 16 below shows the high speed alternator internals. This unit is essentially direct drive (except for the belting speed increase) so no gearing is seen in this design. 


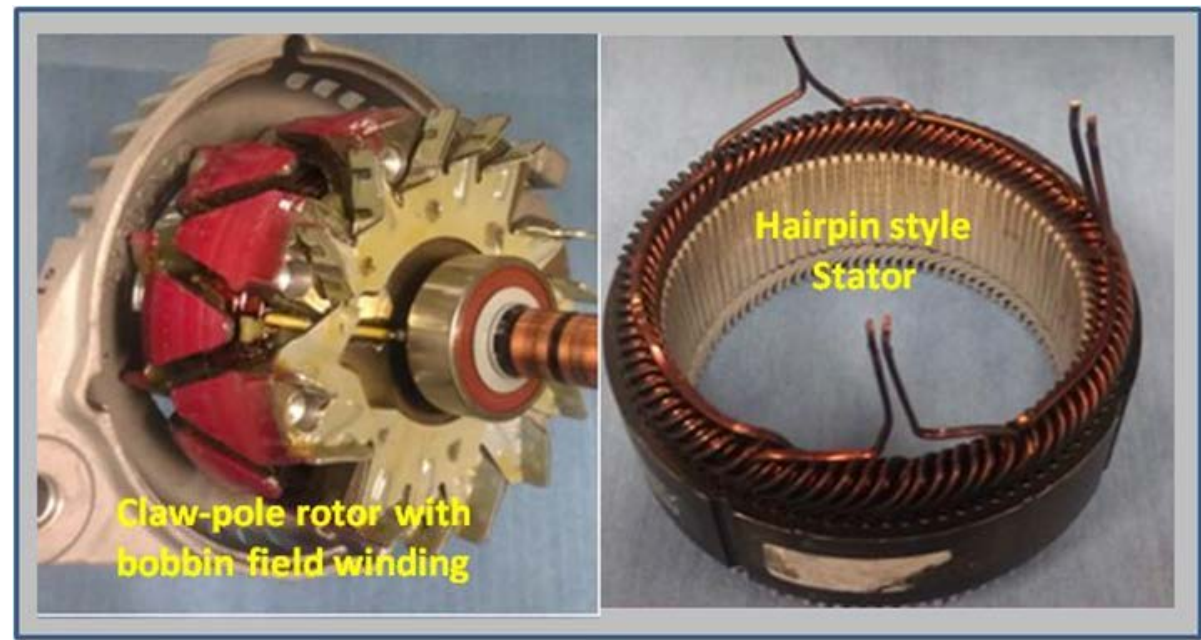

Fig. 16. 2010 Camry high speed alternator, approximately 12000 



\section{SUMMARY}

\subsection{COMPARISON OF GEARING, MANUFACTURING METHODS, AND COSTS BASED ON OBSERVATIONS DURING TEARDOWNS}

Traction drive gearing - the gears in all the traction drives examined looked to be of very similar fabrication and quality, so costs on a per-gear basis should be very similar. The differences in the drive's speed ranges were accomplished by addition of in-line planetary gear reductions around 3 to 1 at the motor output shafts.

A future useful task to further benchmark these drives would be to have several gears analyzed for dimensional accuracy to determine the class of gears they fit in. This could be done for several or all of the benchmarked drives for one or two similar function gears in the drive. Visual inspection indicates they are of the same class, but high accuracy measurements could determine this more reliably.

In a push for higher and higher speeds for motors in traction drive applications, it was thought that bearing speed capabilities would present challenges. Examination of bearings found in the benchmarked units during this study show fairly conventional bearing designs - not special high speed designs as might

be expected. It was also expected that the drives, although achieving higher speeds, would not be designed for higher and higher costs or they would not be able to compete in the market. For this reason high quality spindle-type bearings, for instance, would probably not be a good choice for an automotive drive.

The bearings found in these drives appear to be all conventional type and quality. Checks across the board show that the design intent at the high speed end of these drives utilized shaft sizes, bearing styles, and lubrication that pushed the design speed limit right to the maximum of the bearings without exceeding that. For most of these designs, a 10\% speed increase would create a need for different (more costly) bearings, different lubrication, or other cost-increasing issues.

High speed starter gearing - gearing in these units were studied to look for trends in the starter motor design intentions, and to look for similarities to automotive traction drive design changes as they move towards higher speeds.

Interesting gearing applications were found in these starters - powder metallurgy sintered gears and forged-on-shaft gears for significantly high speeds (15,000-20,000 rpm range). Little or no finishing on most of these gears was seen, i.e. most were probably not ground. This will keep the cost down considerably for these units. There is definitely a trend toward higher speeds with this class of electric machines, but the significant differences in their application to that of traction drives allows significant differences in cost and quality. These motors experience a very low duty cycle, so can utilize peak power as their design power, thermal issues are much reduced, and run time on gears and bearings is extremely reduced. Vibration or rough running for these units is not as much of a concern as in the traction drive as well. Thus, the dissimilarity in what was found is justified. The traction drive gears were all ground and finished - their duty cycle is essentially $100 \%$ and have a huge impact on noise and vibration in the vehicle for long periods of time. All the shafts in the starter units (and the alternator examined) had permanently greased bearings, which based on their smaller size and lower duty cycle, can survive much higher speeds even though greased. These units are also not really suited to oil lubrication (as in traction drives) due to packaging and location, so permanent greasing is a good design choice. 
Table 1 shows a comparison chart for the systems that have been reviewed during this study.

Table 1. Comparison chart for traction drives and starters

\begin{tabular}{|c|c|c|c|c|}
\hline $\begin{array}{l}\text { Vehicle } \\
\text { (Make/year) }\end{array}$ & $\begin{array}{l}\omega_{\text {Motor }} \\
\text { (rpm) }\end{array}$ & $\begin{array}{l}\text { Gear Ratio } \\
\omega_{\text {mot }} / \omega_{\text {whl }}\end{array}$ & $\begin{array}{l}\text { \# of Clutch } \\
\text { Sets }\end{array}$ & $\begin{array}{l}\text { \# of Gears } \\
\text { mtr-diff'I }\end{array}$ \\
\hline 2004 Prius & 6000 & 4.11 & 0 & 6 \\
\hline 2010 Prius & 13500 & 8.61 & 0 & 7 \\
\hline 2007 Camry & 14000 & 8.78 & 0 & 7 \\
\hline LEAF & 10400 & 7.93 & 0 & 4 \\
\hline Sonata & 6000 & 6 spd trans. & 5 sets & 7 \\
\hline 2008 Lexus & 10200 & 2 spd trans & 2 sets & $?$ \\
\hline Tesla & 15000 & 8.275 & 0 & $?$ \\
\hline \multicolumn{5}{|c|}{ 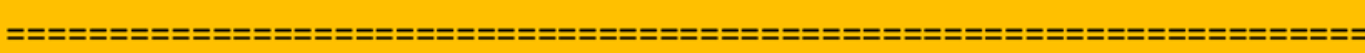 } \\
\hline $\begin{array}{c}\text { Pontiac/Delco } \\
\text { HS starter }\end{array}$ & ? & 1.9 & 0 & $\begin{array}{l}3 \text { to ring } \\
\text { (offset gears) }\end{array}$ \\
\hline $\begin{array}{l}\text { Dixie Electric } \\
\text { starter }\end{array}$ & $9300^{*}$ & 4.29 & 0 & $\begin{array}{l}3 \text { to ring } \\
\text { (planetary) }\end{array}$ \\
\hline $\begin{array}{l}\text { Denso } 280-0172 \\
\text { starter }\end{array}$ & $9000^{*}$ & 4.44 & 0 & $\begin{array}{l}3 \text { to ring } \\
\text { (offset gears) }\end{array}$ \\
\hline $\begin{array}{l}2010 \text { Camry } \\
\text { starter }\end{array}$ & $17000^{*}$ & 7.875 & 0 & $\begin{array}{l}3 \text { to ring } \\
\text { (planetary) }\end{array}$ \\
\hline
\end{tabular}

Table 2 shows documented power density values for the ORNL benchmarked traction drives since the original 2004 Prius (see reference [5]). 
Table 2. Power density comparison of several hybrid/electric vehicles

\begin{tabular}{|c|c|c|c|c|c|c|c|c|c|}
\hline $\begin{array}{l}\text { Component \& } \\
\text { Parameter }\end{array}$ & $\begin{array}{c}2020 \mathrm{DOE} \\
\text { Targets }\end{array}$ & $\begin{array}{c}2012 \text { Leaf } \\
(80 \mathrm{~kW})\end{array}$ & \begin{tabular}{|c|}
2012 \\
Sonata \\
HSG \\
$23(8.5 \mathrm{~kW})$
\end{tabular} & $\begin{array}{c}2011 \\
\text { Sonata } \\
(30 \mathrm{~kW})\end{array}$ & $\begin{array}{c}2010 \\
\text { Prius } \\
(60 \mathrm{~kW})\end{array}$ & $\begin{array}{c}2008 \\
\text { Ls600h } \\
\text { Lexus } \\
(110 \mathrm{~kW})\end{array}$ & $\begin{array}{c}2007 \\
\text { Camry } \\
(70 \mathrm{~kW})\end{array}$ & $\begin{array}{c}2006 \\
\text { Honda } \\
\text { Accord } \\
(12 \mathrm{~kW})\end{array}$ & $\begin{array}{c}2004 \\
\text { Prius } \\
(50 \mathrm{~kW})\end{array}$ \\
\hline \multicolumn{10}{|c|}{ Motor } \\
\hline $\begin{array}{l}\text { Peak pow er density, } \\
\text { kW/L }\end{array}$ & 5.7 & 4.2 & $7.42(2.7)$ & 3.0 & 4.8 & 6.6 & 5.9 & 1.5 & 3.3 \\
\hline $\begin{array}{l}\text { Peakspecific pow er, } \\
\mathrm{kW} / \mathrm{kg}\end{array}$ & 1.6 & 1.4 & $1.9(0.7)$ & 1.1 & 1.6 & 2.5 & 1.7 & 0.5 & 1.1 \\
\hline
\end{tabular}

Below is a graph showing the general relationship of vehicle/motor speeds and their volumetric power density (Figure 17), using the data from Tables $1 \& 2$. In this graph, the motor designs show a linear progression of power density as speed is increased, if we ignore the Lexus data point. The Lexus is a high-priced high performance vehicle, so this design really lies outside the grouping of the other vehicles that are normal large market sedans.

The improvements do not follow the calendar - the 2012 LEAF (all electric) falls in the middle of the line. The 2012 Sonata falls at the bottom with the 2004 Prius. They were apparently not concerned about power density for that design. The 2007 Camry and 2010 Prius power density and speed fall at the highest end of this graph, and they are hybrids with much greater demand on under-the-hood space than the LEAF, being an all-electric, would have.

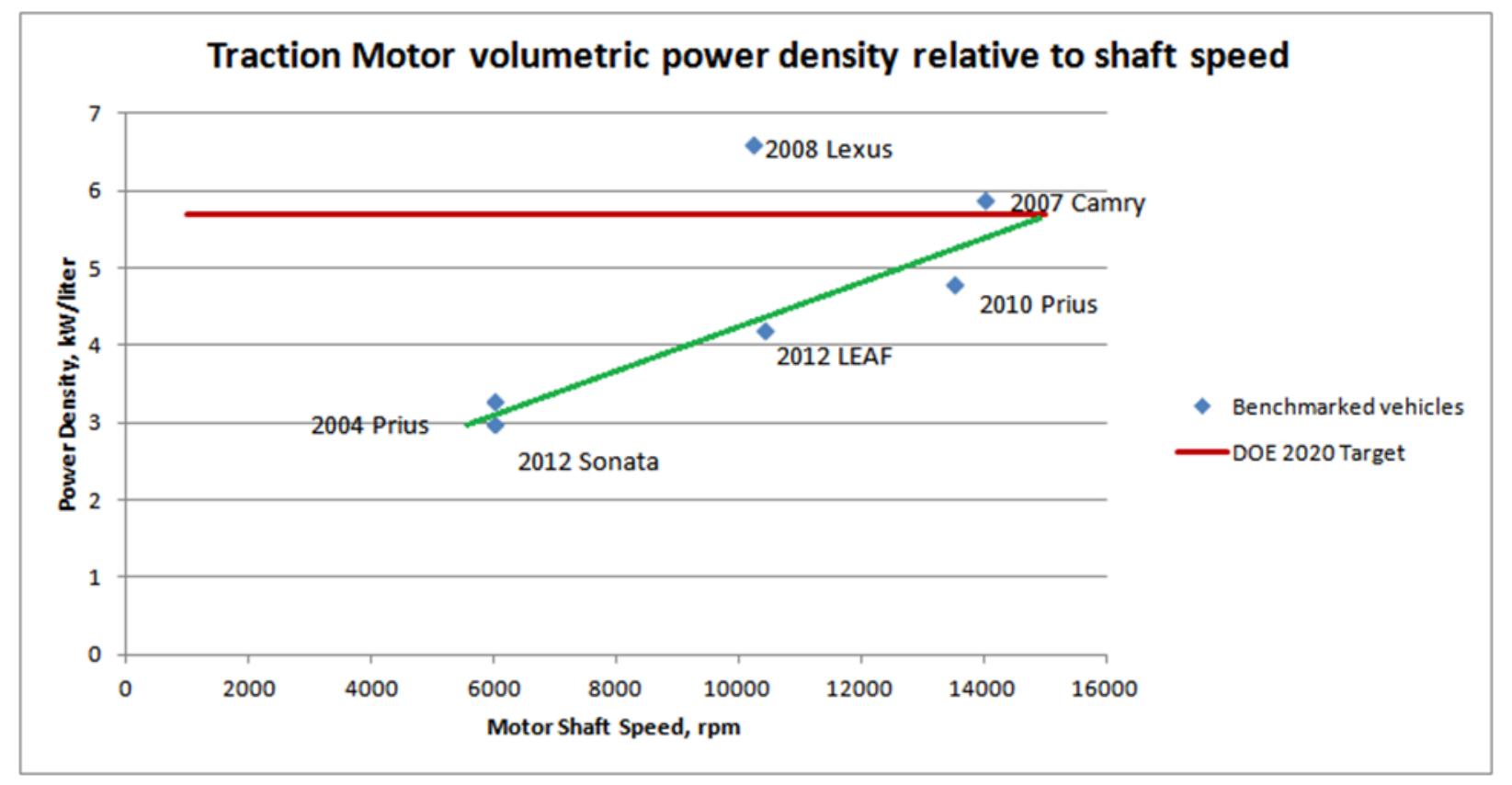

Fig. 17. Graph of traction motor power density relationship to shaft speed 


\section{CONCLUSIONS}

Motor speeds progressed in 2004 from 6000 rpm up to 14,000 rpm by 2012, from the '04 Prius to the '07 Camry and ' 10 Prius, with the motors getting smaller over this period. There was a $45 \%$ increase in power density for the Prius over this period. There was a 79\% increase in power density from the 2004 Prius to the 2007 Camry. The speeds of these vehicles increased about $125 \%$ during this time. The power density increase implies that about half of the copper and silicon steel (and Rare Earth Permanent Magnet material if applicable) would be required for the newer high-speed motors. The mass and volume for the in-line planetaries for the higher speed motors have been included in the data (see Table 2 above). The tradeoff benefit gained here by adding gears is reduced copper, silicon steel, and rare-earth permanent magnet material.

All gears examined from the traction drives use typical fabrication techniques including hobbing/shaping and fine finish grinding operations. There was no innovation such as forged or PM gears in these drives to reduce cost or ease manufacturing.

Bearings in the traction drives appear to be conventional, although non-standard sizes, and no evidence of design intent for high-speed was identified. Estimated speeds for the bearings examined were all at or near the design speed limits for that style and size of bearing, which included mostly deep-groove ball bearings, and needle bearings utilized in the planetary systems. Speed increases were not accomplished via special bearings.

In-line planetary gear sets were utilized to add the additional ratio needed to reach the $>10,000 \mathrm{rpm}$ range (Prius, Camry, and Lexus), with the downstream gears of the driveline being essentially left alone (no design innovations). There is no evidence that special bearings or shafting was utilized to increase speed capability. Speed increases for the benchmarked traction drives were primarily accomplished using a speed reduction planetary at the motor output shaft. Gear reductions for this purpose were about 2.6 to 1 , added to the existing ratio in the downstream driveline gears for the respective drive.

Bearings and lubrication will present the new boundaries for traction drive design as speeds progress above 15-20 krpm. Cost tradeoff research will be needed to determine the point of diminishing returns on speed increases for this application.

Gear forming in the subject starters uses more economical methods, with some of the gears having no finishing procedures (grinding). These are high speed machines, but have a very low duty cycle compared to traction drives. Forging of gears on their shaft is one procedure and powder metallurgy fabrication is another common method being used on these gear sets.

Bearings in the high-speed starters are conventional, and all were packed-grease lubrication. Grease style bearings typically have a lower speed rating, but the sizes of these units were small enough diameter to allow permanent grease lubrication for their speed ranges. Also the low duty cycle of these designs allows greased bearings to operate at much higher speeds. 


\section{ACKNOWLEDGEMENTS}

Thanks to Steven Campbell, Chester Coomer, and Tim Burress for their help on this study for background on benchmarking teardowns and gear study. Steven's and Chester's support was valuable as well during extended examinations of the benchmarked traction drives and the starter/alternator teardowns and examinations. 


\section{REFERENCES}

1. “Report on Toyota/Prius Motor Design and Manufacturing Assessment”, J. S. Hsu, C. W. Ayers, C. L. Coomer, Oak Ridge National Laboratory ORNL/TM-2004/137, July 2004

2. "Evaluation of the 2010 Toyota Prius Hybrid Synergy Drive System, T. A. Burress, S. L. Campbell, C. L. Coomer, C. W. Ayers, A. A. Wereszczak, J. P. Cunningham, L. D. Marlino, L. E. Seiber, H. T. Lin, Oak Ridge National Laboratory ORNL/TM-2010/253, March 2011

3. "Evaluation of the 2007 Toyota Camry Hybrid Synergy Drive System, T. A. Burress, C. L. Coomer, S. L. Campbell, L. E. Seiber, L. D. Marlino, R. H. Staunton, J. P. Cunningham, Oak Ridge National Laboratory ORNL/TM-2007/190, April 2008

4. "Evaluation of the 2008 Lexus LS600H Hybrid Synergy Drive System, T. A. Burress, C. L. Coomer, S. L. Campbell, A. A. Wereszczak, J. P. Cunningham, L. D. Marlino, L. E. Seiber, H. T. Lin, Oak Ridge National Laboratory ORNL/TM-2008/185, December 2008

5. "Benchmarking State-of-the-Art Technologies", T. A. Burress, 2013 U.S. DOE Hydrogen and Fuel Cells Program and Vehicle Technologies Program Annual Merit Review and Peer Evaluation Meeting, May $14^{\text {th }}$, 2013, Project ID: APE006 



\section{INTERNAL DISTRIBUTION}

1. K. P. Gambrell

2. J. M. Miller

3. B. Ozpineci

\section{EXTERNAL DISTRIBUTION}

4. R. R. Fessler, BIZTEK Consulting, Inc., 820 Roslyn Place, Evanston, Illinois 60201-1724.

5. M. W. Lloyd, Energetics, Inc., 7164 Columbia Gateway Drive, Columbia, Maryland 21046.

6. N. Olds, United States Council for Automotive Research (USCAR), nolds@uscar.org

7. S. A. Rogers, U.S. Department of Energy, EE-2G/Forrestal Building, 1000 Independence Avenue, S.W., Washington, D.C. 20585. 